\title{
Elucidation of peptide metabolism by on-line immunoaffinity liquid chromatography mass spectrometry
}

\author{
Kefei Zheng ${ }^{1}$, David M. Lubman ${ }^{1}$, David T. Rossi ${ }^{2}$, Gerald D. Nordblom ${ }^{2}$ and \\ Charles M. Barksdale \\ ${ }^{1}$ Department of Chemistry, The University of Michigan, Ann Arbor, MI 48109-1055, USA \\ ${ }^{2}$ Department of Pharmacokinetics, Dynamics and Metabolism, Parke-Davis Pharmaceutical Research, Division of Warner- \\ Lambert Co., Ann Arbor, MI 48105, USA
}

\begin{abstract}
An immunoaffinity chromatography extraction capillary liquid chromatography separation has been coupled to electrospray ionization mass spectrometry for on-line characterization of drug metabolites of a therapeutic peptide in plasma. It is demonstrated that the selectivity, sensitivity and molecular weight data provided by immunoaffinity chromatography coupled to liquid chromatography/mass spectrometry provides a means of rapidly achieving qualitative determinations of small amounts of material in complicated biological matrices such as plasma. The ability to detect the peptide in rat plasma at a level of $10 \mathrm{ng} / \mathrm{mL}$ is demonstrated using this method. In addition, experiments to study the epitope of the peptide by enzymatic digestion and mass spectrometry are also discussed. The method is proposed as an alternative approach to studying the metabolism of therapeutic peptides. Copyright (C) 2000 John Wiley \& Sons, Ltd.
\end{abstract}

Received 25 October 1999; Revised 14 December 1999; Accepted 15 December 1999

It has become increasingly important to elucidate and understand the metabolism of therapeutic peptides. Such information has become essential for understanding the mechanisms of drug action, the utilization of clearance pathways, the nature and extent of metabolism-induced toxicity, the effect of race or gender differences on drug efficacy and other important pharmacological questions. The study of in vivo metabolism of therapeutic drugs has traditionally required a chemical synthesis to incorporate a radioisotope (usually ${ }^{14} \mathrm{C}$ ) into the molecular structure at a strategic location. If the target molecule is designed correctly, it can undergo biotransformations while retaining the radiolabel. After dosing the labeled drug and collecting biological-fluid samples, a metabolite profile is obtained using chromatographic separation and radiometric detection of the labeled analytes. This approach is problematic for therapeutic peptides in that extensive and rapid metabolism involving amide bond cleavage makes the loss of the radiolabel much more facile. This creates the dilemma of obtaining very different metabolic profiles if different label locations are used.

Several approaches have been developed in attempts to minimize amide bond cleavage and incipient loss of radiolabel for therapeutic peptides. These include: (i) placing the radiolabel on an unnatural residue such as a Damino acid, where biological demand is low and there is poor recognition by proteases; (ii) placing the label on the amino acid residue with the poorest biological reincorpora-

*Correspondence to: D. T. Rossi, Department of Pharmacokinetics, Dynamics and Metabolism, Parke-Davis Pharmaceutical Research, Division of Warner-Lambert Co., Ann Arbor, MI 48105, USA.

E-mail: david.rossi@wl.com

Contract/grant sponsor: National Institutes of Health; Contract/grant number: ROIGM 49500.

Contract/grant sponsor: Parke-Davis Pharmaceutical Research. tion; (iii) using multiple radiolabel sites to ensure the retention of the radiophore in the molecular backbone. The latter option can result in data that are convoluted and difficult to interpret. In practice, dosing of a radiolabeled drug is only a starting point for structural elucidation of metabolites. Subsequent characterization by liquid chromatography/tandem mass spectrometry (LC/MS/MS) experiments is generally required. ${ }^{1}$ Even then, if the radiolabeled moiety is lost from the peptide, there is a real possibility of overlooking a major, biologically active peptide fragment.

Immunoaffinity chromatography (IAC) differs from conventional chromatography in that, rather than differential solubility, it employs specific biological/biochemical interactions associated with an antibody and antigen. This high degree of selectivity becomes particularly important with therapeutic drug analysis because the drug and metabolites must be detected at low levels from among a large number of potentially interfering species in a complex plasma sample. In previous work, IAC has demonstrated selective sample enrichment which has been shown to be effective in extracting a peptide drug and metabolites from plasma and other biological matrices at the detection level required for such characterization. ${ }^{2-4}$ After the non-binding components have been washed from the immunoaffinity column, a denaturing solution can be used to elute the antigens for further separation and characterization. A more definitive characterization of the peptide metabolites can then be achieved using either electrospray ionization (ESI) or matrix-assisted laser desorption/ionization (MALDI) mass spectrometry.

Several papers describing permutations of this combined approach of immunoaffinity-liquid chromatography/electrospray ionization mass spectrometry (IA-LC/ESI-MS) have been published for quantitative determinations of small organic molecules in biofluids. ${ }^{5-9}$ A related approach, 


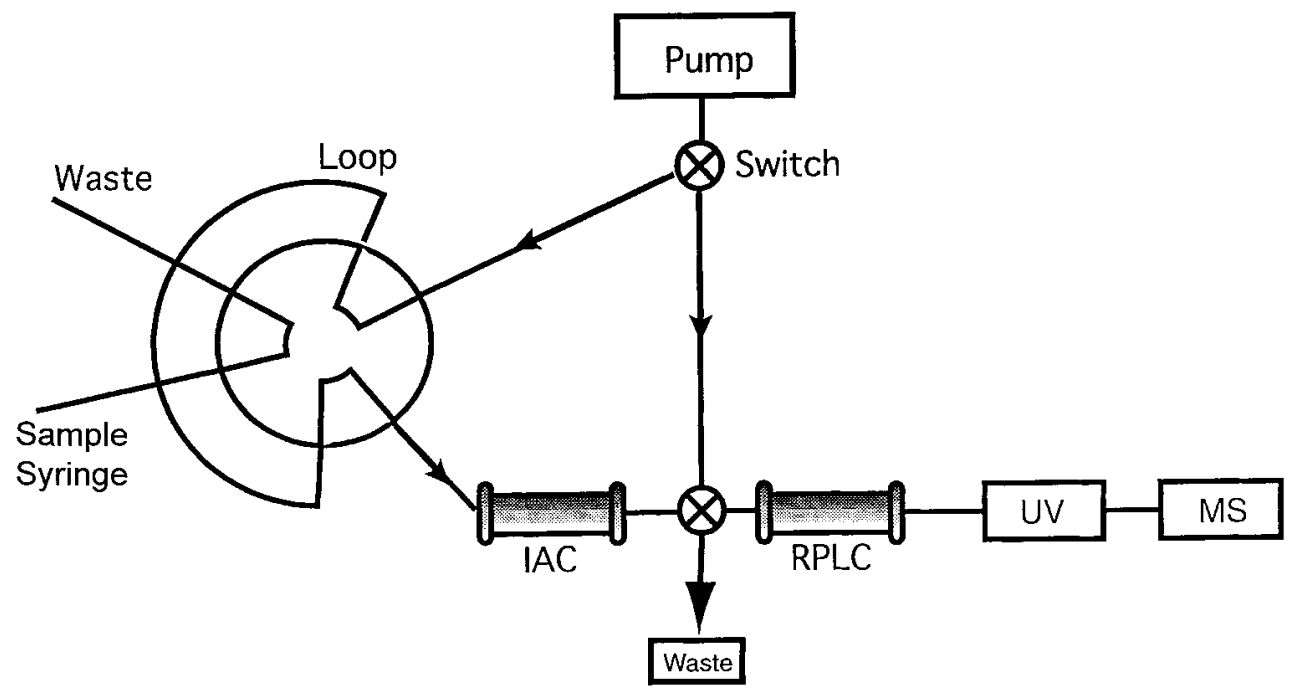

Figure 1. Experimental setup of the immunoaffinity chromatography experiment.

involving immunoaffinity extraction and matrix-assisted laser desorption/ionization time-of-flight mass spectrometry (MALDI-TOFMS) has been used for rapid qualitative screening of human blood for the presence of myotoxin $\mathrm{A},{ }^{10}$ for the identification of metal binding proteins and phospholipids, ${ }^{11}$ and for the screening of combinatorial libraries. ${ }^{12}$ To our knowledge, the IAC/LC/MS approach has not been applied as a tool for the study of therapeutic peptide metabolism, either in on-line or off-line configurations.

In the present work, we demonstrate the feasibility of elucidating the metabolism of a therapeutic peptide by combining IAC/capillary LC ( $\mu \mathrm{LC}$ ) coupled to ESI-MS for on-line characterization of metabolites of a therapeutic peptide in plasma. The immunoaffinity separation selectively retains parent drug and any metabolic fragments that have sufficiently conserved structures. These analytes can then be separated by reversed-phase chromatography and characterized mass spectrometrically. The ability to detect the peptide in plasma at the desired levels and an attempt to study the binding of the peptide to the antibody by enzymatic digestion and mass spectrometry is demonstrated herein. The drug used in this work, SNX-111, is a 25 amino acid peptide (isotope-averaged molecular weight 2639.2,

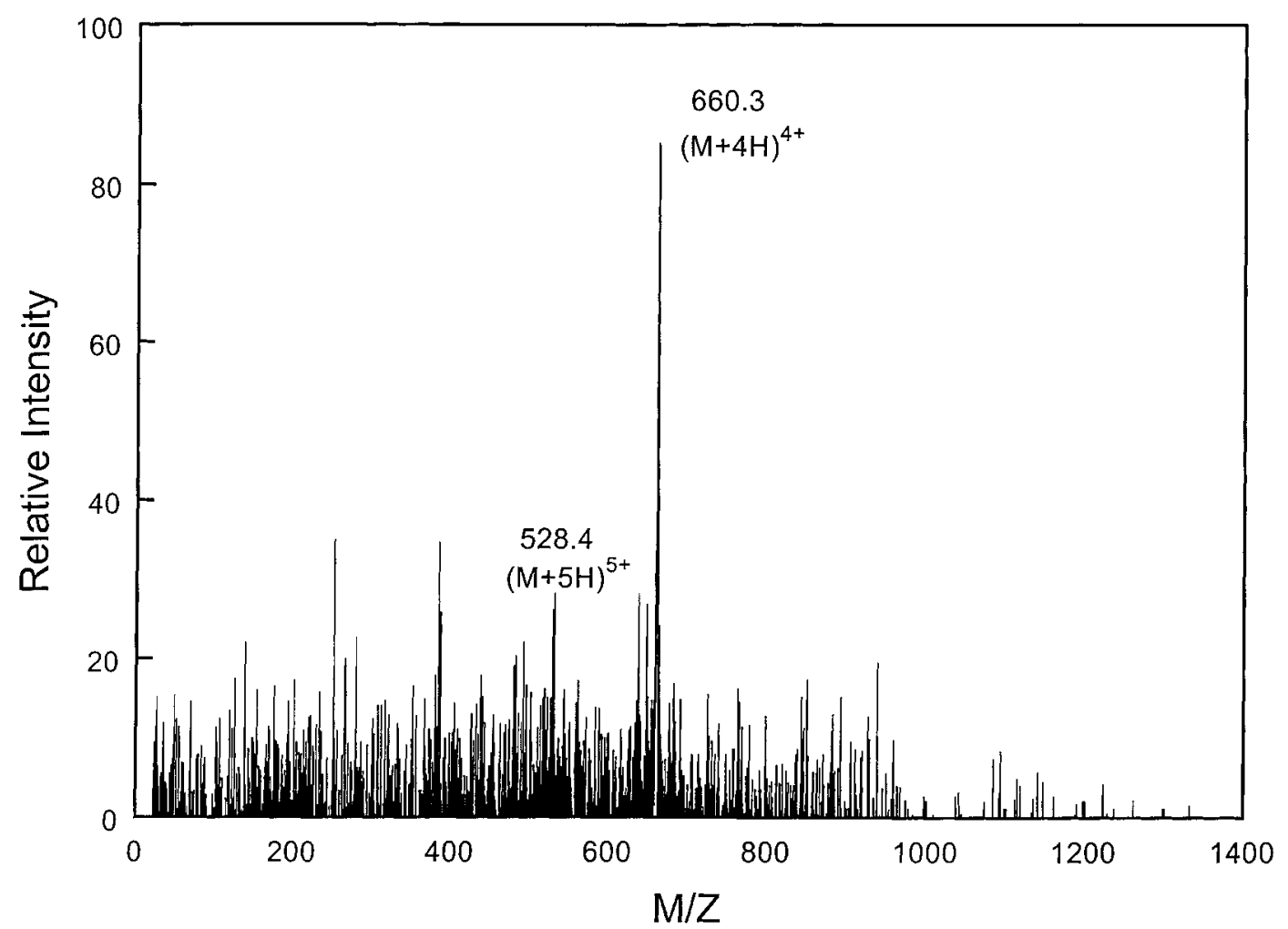

Figure 2. Mass spectrum of SNX-111 from LC/MS experiment ( $3 \mu \mathrm{L}$ of $20 \mathrm{ng} / \mu \mathrm{L}$ on-column) in acetonitrile/ water/ TFA (50:50:0.1\% v/v). 
monoisotopic molecular weight 2636.1 ) produced by solidphase synthesis. It is identical in chemical structure to Conotoxin M VIIA, obtained from natural sources. ${ }^{13}$ It has three internal disulfide bonds with the sequence as follows: aliquot $(15 \mathrm{~mL})$ of the pooled polyclonal antiserum from the rabbits was loaded on a Protein A-Sepharose column $(2 \times 6 \mathrm{~cm}$, glass) and the $\mathrm{IgG}$ eluted with $30 \mathrm{~mL}$ of glycine buffer (0.1 M, pH 3.0). The eluted IgG was then dialyzed

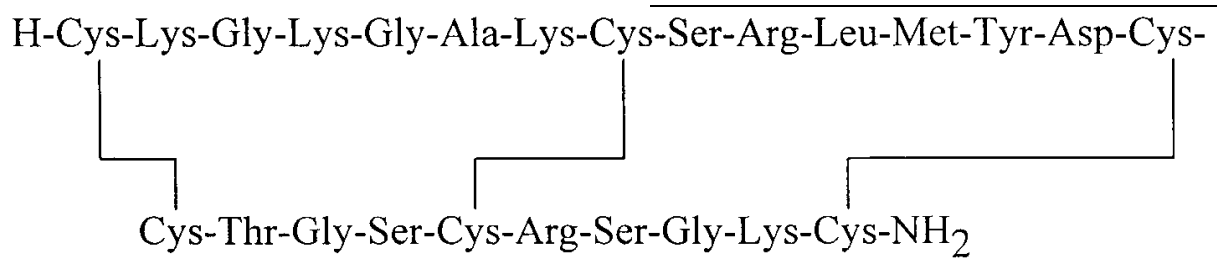

SNX-111 was chosen as a model analyte because of the availability of the antibody to this compound and its potential usage as a therapeutic drug.

\section{EXPERIMENTAL}

\section{Materials}

SNX-111 acetate was manufactured by Adria-SP, Inc (Albuquerque, NM, USA). SNX-279 (MW 2653), a methionine $S$-oxide metabolite of SNX-111, was obtained from Neurex Corp. (Menlo Park, CA, USA). Trifluoroacetic acid (TFA) was purchased from Sigma Chemical Co. (St. Louis, MO, USA).HPLC grade acetonitrile, methanol and Tris were obtained from Aldrich (Milwaukee, MN, USA). C18 packing materials $(5-\mu \mathrm{m}$ silica particles, $300-\AA$ pore size) were from Vydac (Hesperia, CA, USA). Enzymes were purchased from Promega Corporation (Madison, WI, USA), including clostripain, endoproteinase Lys-C, modified trypsin and proteinase K. Rat plasma was produced from EDTA anticoagulated blood collected from male Wistar rats.

\section{Antibody preparation}

Preparation of SNX-111 bovine serum albumin. Bovine serum albumin (BSA) was dissolved at $20 \mathrm{mg} / \mathrm{mL}$ in $14 \mathrm{~mL}$ of distilled water in a 50-mL polypropylene flask. SNX-111, at $10 \mathrm{mg} / \mathrm{mL}$ in $7 \mathrm{~mL}$ of water, was added $(2: 1 \mathrm{ratio} ; \mathrm{v} / \mathrm{v})$ and the mixture slowly stirred to mix at room temperature. The conjugation was initiated by the drop-wise addition of 1-ethyl-3-(3-dimethylaminopropyl)carbodiimide, at $50 \mathrm{mg} /$ $\mathrm{mL}$ in $700 \mu \mathrm{L}$ of water. The reaction was gently stirred overnight at $4{ }^{\circ} \mathrm{C}$, then centrifuged for $20 \mathrm{~min}$ in a Beckman TJ6 centrifuge. The resulting precipitate was mixed with $50 \mathrm{~mL}$ of $0.01 \mathrm{M}$ ammonium bicarbonate buffer, $\mathrm{pH}$ 8.0. One-mL aliquots (equivalent to $1 \mathrm{mg}$ SNX-111 $+4 \mathrm{mg}$ BSA) were placed in 5-mL screw-cap vials, lyophilized to dryness, and stored at $4{ }^{\circ} \mathrm{C}$ until use. Spectrophotometric analysis of the resulting conjugate indicated 4.5 moles of SNX-111 per mole BSA.

Immunization of rabbits. Antibody was raised in rabbits at Josman Laboratories (Napa, CA, USA). Four rabbits were immunized with $1.25 \mathrm{mg}$ of SNX-111-BSA immunogen in a Freund's complete adjuvant and normal saline $(1: 1 ; \mathrm{v} / \mathrm{v})$ emulsion with a biweekly schedule of injections over a period of 3 months until adequate titers and sensitivities were obtained. As previously reported, ${ }^{3}$ the sera from the best responding rabbits (NXJ 149 and NXJ 150) were harvested, and subsequently pooled to provide SNX-111 antiserum used in the RIA.

Rabbit anti-SNX-111 immunoglobulin $G$ isolation. An against sodium bicarbonate buffer $(0.1 \mathrm{M}, \mathrm{pH} 8.8)$ and aliquotted for long term storage at $-20^{\circ} \mathrm{C}$. $^{2}$

Preparation of Rabbit anti-SNX-111 IgG-CNBr-Sepharose$4 B$ Immunoaffinity gel. Isolated polyconal rabbit anti-SNX$111 \mathrm{IgG}(60 \mathrm{mg})$ in $15 \mathrm{~mL}$ of buffer $\mathrm{A}(0.1 \mathrm{M}$ sodium bicarbonate, $\mathrm{pH} 8.8$, containing $0.5 \mathrm{M} \mathrm{NaCl}$ ) was added to $6.0 \mathrm{~g}$ of CNBr treated Sepharose-4B gel in $100 \mathrm{~mL}$ of 0.001 $\mathrm{M} \mathrm{HCl}$, in a $25 \times 250 \mathrm{~mm}$ glass column. The column ends were plugged, and the column was then rotated gently, with the gel reagents mixing for $2 \mathrm{~h}$ at $22^{\circ} \mathrm{C}$. After draining the solvent, $100 \mathrm{~mL}$ of buffer A containing $1.0 \mathrm{M} 2$-aminoethanol was added to the remaining gel. After mixing for $2 \mathrm{~h}$, the column was run dry and the gel washed four times with the sequence of $100 \mathrm{~mL}$ of buffer $\mathrm{A}$, followed by $100 \mathrm{~mL}$ of sodium acetate $(0.1 \mathrm{M}, \mathrm{pH} 4.0)$ containing $0.5 \mathrm{M} \mathrm{NaCl}$. The gel was then equilibrated with phosphate buffered saline $(\mathrm{pH} 7.40)$ and stored at $4^{\circ} \mathrm{C}$ until used to pack the immunoaffinity HPLC column. Fresh $\left[{ }^{125} \mathrm{I}\right]-\mathrm{SNX}-111^{2}$ of known radioactivity was used to characterize the binding capacity of the Sepharose-4B-IgG gel for SNX-111.

\section{Column packing}

The microbore immunoaffinity column and the reversedphase capillary columns were packed in-house using the following procedure: for the reversed-phase capillary column, C18 bonded phase silica particles were first suspended in methanol in a stirring tank. The suspension was then loaded into a high-pressure fitting attached at one end to the column blank that was a $15-\mathrm{cm}$ length of $250 \mu \mathrm{m}$ i.d./350 $\mu \mathrm{m}$ o.d. fused silica capillary (Polymicro Technologies, Phoenix, AZ, USA). The other end of the fitting was attached to the outlet of a high-pressure syringe pump (ISCO, $\mu$ LC-500 micropump, Lincoln, NE, USA). The packing pressure was increased to 5500 psi gradually as the packing proceeded, then allowed to drop slowly following completion of the packing process.

For the microbore immunoaffinity column, Sepharose-4B gel $(\sim 1 \mathrm{~mL})$ immobilized SNX-111 antibody was suspended in $50 \mathrm{mM}$ of Tris buffer $(\mathrm{pH}=7.5)$. PEEK tubing $6 \mathrm{~cm} \times 1 / 16$ in $\times 1.0 \mathrm{~mm}$ i.d. (Alltech Associates, Inc., Deerfield, IL, USA) was substituted for the fused-silica capillary used in the reversed-phase process. A lower packing pressure (100-150 psi) was used to prevent crushing of the Sepharose-4B particles. For some experiments, a $2.1 \mathrm{~mm} \times 10 \mathrm{~cm}$ empty PEEK column (Upchurch Scientific, Oak Harbor, WA, USA) was packed with immunoaffinity gel by a similar process. A $2.0 \times 25 \mathrm{~cm}$ reversed-phase C18 column (Vydac, Hesperia, CA, USA) was used in tandem with this larger bore immunoaffinity column. For these larger scale columns, a flow rate of $200 \mu \mathrm{L} / \mathrm{min}$ and injection volumes of $10 \mu \mathrm{L}$ were used. 


\section{Chromatographic system}

The column switching and HPLC system consisted of a Star 9012 solvent delivery system (Varian Associates, Inc., Walnut Creek, CA, USA), two Valco Model C6W valves (Valco Instruments Co. Inc., Houston, TX, USA) equipped with a $10-\mu \mathrm{L}$ external sample loop, and a Star 9050 (Varian) variable wavelength UV detector. For some experiments, a series 200 chromatograph (Perkin-Elmer, Norwalk, CT, USA) equipped with dual high-pressure mixing binary gradient pumps and an autosampler, and a 10-port electrically activated switching valve (Valco Instruments) was used. To minimize the dead-volume during the UV monitoring process, the original $4.5-\mu \mathrm{L}$ flow cell in the UV detector was replaced with a $60-\mathrm{nL}$ microcapillary flow cell. A valve located immediately before the injection point was used to split (40:1) the mobile phase flow, to reduce the normal flow rate from 200 to $5 \mu \mathrm{L} / \mathrm{min}$ for the capillary column. The analytical column that followed the immunoaffinity column was a fused-silica capillary $(0.25 \mathrm{~mm}$ i.d. $\times 150 \mathrm{~mm}$ ) packed with a 5- $\mu \mathrm{m}$ Vydac C18 $218 \mathrm{TP}$ stationary phase. The end of the column was connected directly to a piece of $75-\mu \mathrm{m}$ i.d. fused-silica capillary terminated at the electrospray needle assembly. The use of a packed capillary column has several advantages, including improved mass sensitivity and easy coupling to a mass spectrometer. This microbore immunoaffinity column also increased the sensitivity and could be operated at a low flow rate $(5 \mu \mathrm{L} / \mathrm{min})$ compatible with the capillary HPLC analytical column under electrospray conditions. Thus, no post-column flow splitting or trapping column was needed.

Aliquots $(4 \mu \mathrm{L})$ of rat plasma or aqueous buffer sample containing SNX-111 and/or other analytes of interest were directly injected onto the immunoaffinity column. Isocratic chromatographic conditions were used for both the analyte loading and elution processes. The immunoaffinity loading buffer was $50 \mathrm{mM}$ Tris at near-physiological $\mathrm{pH}(\mathrm{pH}=7.5)$. Unretained and weakly bound sample components were washed from the immunoaffinity column and passed to waste. All analytes (antigens), as recognized by the immunoaffinity process, were retained. A step-wise solvent switch (to 10:90 acetonitrile: water, with $0.1 \%$ TFA) reversibly denatured the antibodies, thus allowing release of analytes from the immunoaffinity column, concentrating them at the head of the reversed-phase (RP) column. The pump was switched to the capillary analytical column and a higher percentage of acetonitrile eluent solution (30:70 acetonitrile : water containing $0.1 \%$ TFA) was used to elute the bound analytes from the RP column and into the mass spectrometer. At the end of each run, the immunoaffinity column was re-equilibrated with $50 \mathrm{mM}$ Tris buffer, prior to introduction of the next sample. Eluents leaving the columns were also monitored by a UV detector at $214 \mathrm{~nm}$. The detector was digitized through a 16-bit analog-to-digital converter board embedded in a 486 PC compatible computer. Figure 1 shows the experimental setup of the column switching arrangement used.

\section{Mass spectrometry}

An ion trap storage/reflectron time-of-flight (IT/reTOF) mass spectrometer, which consists of a differentially pumped reflectron time-of-flight mass spectrometer (model D850) interfaced to a quadrupole ion trap storage device (Model C-1251, R. M. Jordan Co., Grass Valley, CA, USA), was used for detection. The details of this instrument have been described in previous publications. ${ }^{14}$ For some experiments involving the isolation of compound and $S$ oxide from rat plasma, an API-365 triple quadrupole mass spectrometer (PE-SCIEX, Toronto, CA, USA) equipped with a Turbo ionspray interface was used.

\section{RESULTS AND DISCUSSION}

\section{Characterization of immunoaffinity column capacity}

Using fresh $\left[{ }^{125} \mathrm{I}\right]$ SNX-111 it was found that the swollen Sepharose-4B-IgG gel bound approximately $3 \mu \mathrm{g}$ of SNX111 per $\mathrm{mL}$. The microbore IA column used in these experiments was $6 \mathrm{~cm} \times 1 \mathrm{~mm}$ i.d., with a corresponding volume of $0.047 \mathrm{~mL}$. This calculates to a total binding capacity of $0.14 \mu \mathrm{g}$ of SNX-111 equivalent for the column. A larger IA column, used in some of the narrow-bore $(2.1 \mathrm{~mm})$ work, had column volume and binding capacity of $0.35 \mathrm{~mL}$ and $1000 \mu \mathrm{g}$ equivalents, respectively.

Table 1. Enzymatic digest fragments retained by the immunoaffinity column

\begin{tabular}{|c|c|c|c|c|c|c|}
\hline & & ys-C dige & & & ypsin dige & \\
\hline & Fragment & $\begin{array}{l}\text { Mass } \\
\text { calc. }\end{array}$ & $\begin{array}{l}\text { Mass } \\
\text { seen }\end{array}$ & Fragment & $\begin{array}{l}\text { Mass } \\
\text { cals. }\end{array}$ & $\begin{array}{l}\text { Mass } \\
\text { seen }\end{array}$ \\
\hline Breaking & CK & 249.3 & not obs. & CK & 249.3 & Not obs. \\
\hline the & GK & 203.2 & 204.1 & GK & 203.2 & 204.1 \\
\hline disulfide & GAK & 274.3 & 274.9 & GAK & 274.3 & 274.9 \\
\hline bond & CSRLMYDC & 990.2 & 989.7 & CSR & 364.4 & 365.3 \\
\hline & CTGSCRSGK & 898.0 & 897.2 & SGK & 290.3 & Not obs. \\
\hline & $\mathrm{C}$ & 121.1 & 122.0 & LMYDC & 643.8 & Not obs. \\
\hline & & & & CTGSCR & 625.7 & Not obs. \\
\hline & & & & C & 121.1 & 121.7 \\
\hline Without & GK & 203.2 & 204.1 & GK & 203.2 & 204.1 \\
\hline breaking & GAK & 274.3 & 275.0 & GAK & 274.3 & 275.0 \\
\hline the & CTGSCRSGKC & 2204.6 & 2235.0 & SGK & 290.3 & Not obs. \\
\hline disulfide & 1 & & & CTGSCR & 1203.4 & 1204.5 \\
\hline bond & CK CSRLMYDC & & & $1 /$ & & \\
\hline & & & & LMYDC-C & 746.9 & Not obs. \\
\hline
\end{tabular}




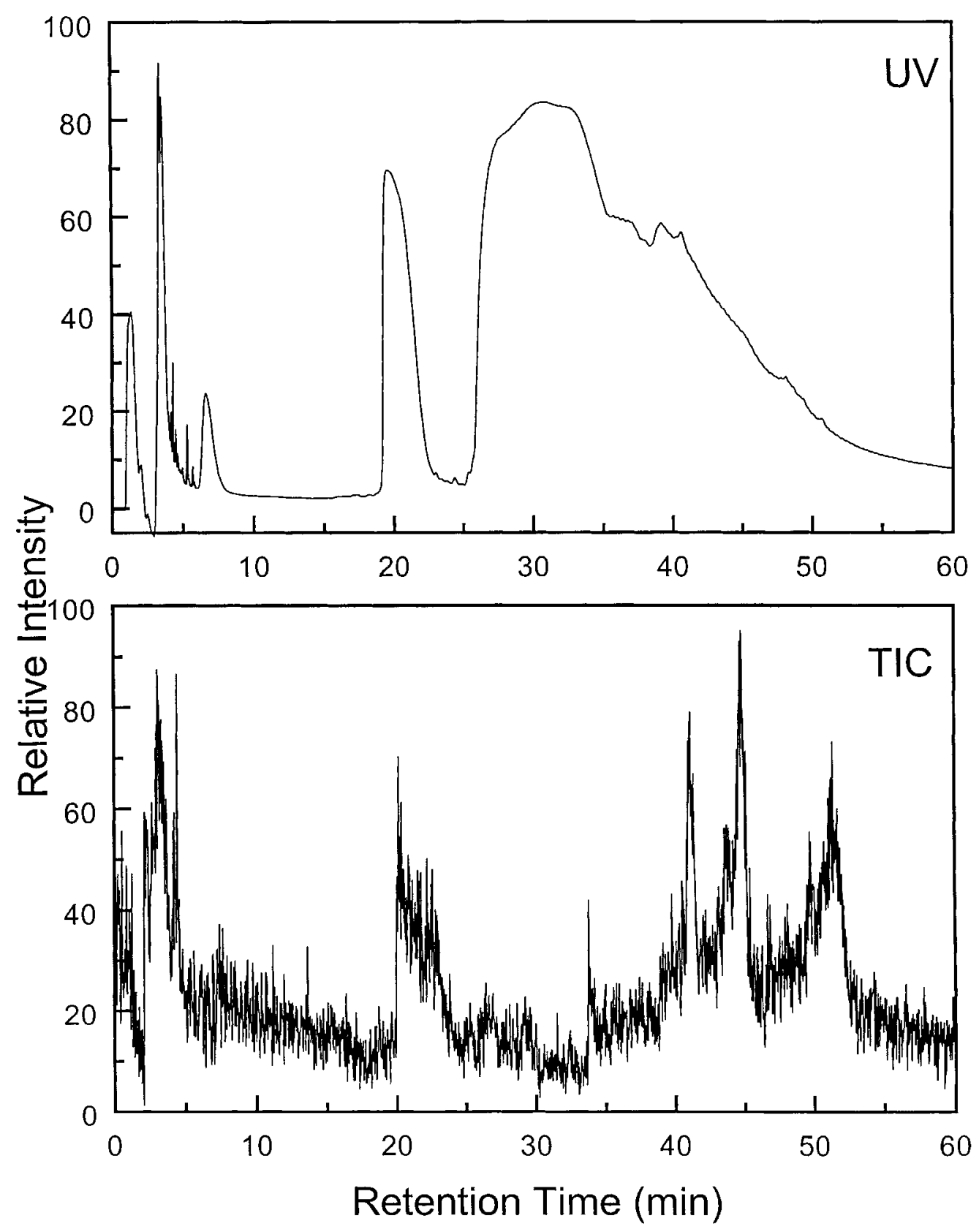

Figure 3. UV chromatogram and total ion chromatogram of plasma mixture after separation by a capillary reversedphase column without the use of the immunoaffinity column in the setup of Fig. 1.

\section{Mass spectrometry}

Proteins and peptides are known to be multiply charged in electrospray ionization mass spectrometry. The profiles of charge state distributions are a function of solution $\mathrm{pH},{ }^{15}$ solvent composition, ${ }^{16}$ instrumental conditions, ${ }^{17}$ temperature, ${ }^{18}$ presence of detergent, ${ }^{19}$ the number of basic or acidic sites, ${ }^{20}$ the solution ionic strength ${ }^{21}$ and protein conformation. ${ }^{22}$ A strong correlation has been observed between the number of basic amino acid residues present in the peptides and proteins and the distribution of charge states observed in its positive ESI spectrum. Figure 2 shows a mass spectrum of a sample of SNX-111, obtained using LC/MS with electrospray ionization on the IT/reTOF mass spectrometer. This resulted in multiply charged $[\mathrm{M}+4 \mathrm{H}]^{4+}$ and $[\mathrm{M}+5 \mathrm{H}]^{5+}$ ions at $\mathrm{m} / \mathrm{z} 660.4$ and 528.4 , respectively. No mass spectrometry fragment ions were observed under these conditions, possibly because of the high degree of disulfide cross-linking in the molecule, which makes fragmentation difficult. Signal-to-noise $(\mathrm{S} / \mathrm{N})$ ratio for this experiment was limited by the performance of the instrumentation, with the $\mathrm{S} / \mathrm{N}$ for the $\mathrm{m} / \mathrm{z} 528$ ion only marginally distinguishable from baseline noise.

\section{Characterization of immunoaffinity antigen recognition}

To gain understanding of antigen recognition and binding, several enzymatic digestions using trypsin, endoproteinase Lys- $\mathrm{C}$ and proteinase $\mathrm{K}$ were performed on the peptide in clean solution. The digestions were performed before and after the dithiothreitol reduction of disulfide cross linkages (3 present). Structural assignments of all digest fragments 


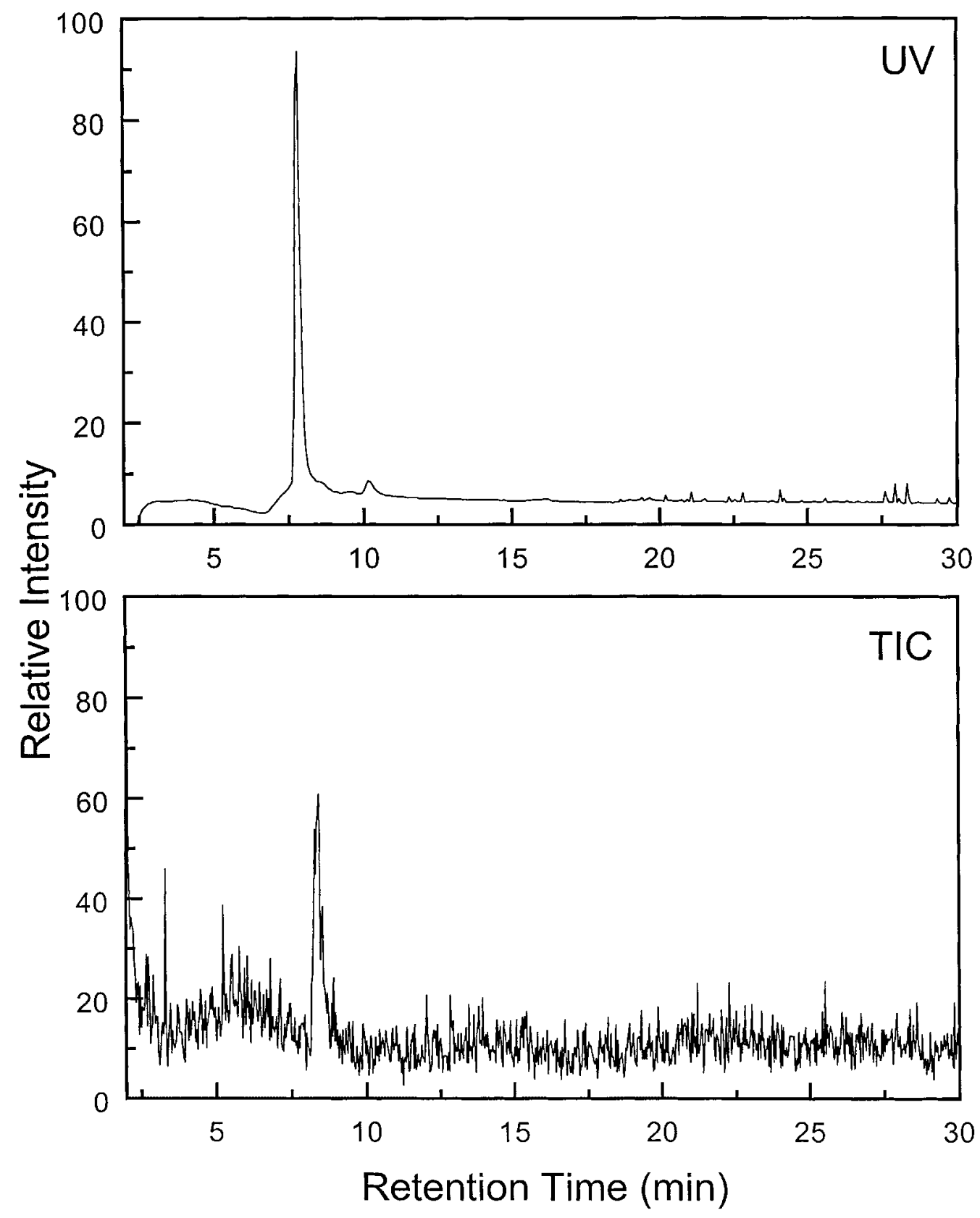

Figure 4. UV detection and the total ion chromatogram of the bound analytes from the plasma sample following elution of the sample from the immunoaffinity column.

were based simply on mass-to-charge ratios $(\mathrm{m} / \mathrm{z})$ obtained by LC/MS rather than sequence characterization by tandem mass spectrometry. The results show that the disulfide bond is critical in terms of forming the antigen/antibody-binding site. Otherwise, due to the multiple cleavages (5 Arg and Lys residues in SNX-111) in the trypsin digest, no specific binding was clearly demonstrated and most of the fragments were not retained. Proteinase $\mathrm{K}$ exhibits very low cleavage specificity as it cleaves at the carboxylic sides of aromatic, hydrophobic and aliphatic amino acids. The fragments from these digests were too small to show affinity to the antigen. In the Lys-C digest without disulfide bond reduction, a large fragment with $[\mathrm{M}+2 \mathrm{H}]^{2+}$ and $[\mathrm{M}+3 \mathrm{H}]^{3+}$ ions at $\mathrm{m} / \mathrm{z}$ 1117.5 and 745.2 was retained along with the original SNX111 on the immunoaffinity column, while small fragments were unretained. It appears as if this fragment is an adduct form of the large fragment at $\mathrm{m} / \mathrm{z} 2204.6$ (Table 1). In the trypsin digest, a fragment with $m / z, 1204.5$ was also retained on the immunoaffinity column. The structure of this fragment is very similar to that of the fragment observed in the Lys-C digest at $m / z 1117.5$ and 745.2, in that both contain KC-CTGSCR-CSR. It is reasonable to suppose that the above fragment contains the epitope or antibody binding site. As long as this binding site is conserved within the peptide fragment, it will be bound and retained by the immunoaffinity column.

Figure 3 shows the UV and total ion chromatograms (TICs) obtained by injecting $4 \mu \mathrm{L}$ of rat plasma sample (with a spiked concentration of $0.2 \mu \mathrm{g} / \mu \mathrm{L}$ SNX-111) onto the capillary reversed-phase column system, followed by mass detection without the benefit of sample cleanup from the immunoaffinity column. The peak for SNX-111 (retention time of approximately $8 \mathrm{~min}$ ) could barely be distinguished from the endogenous components of the 


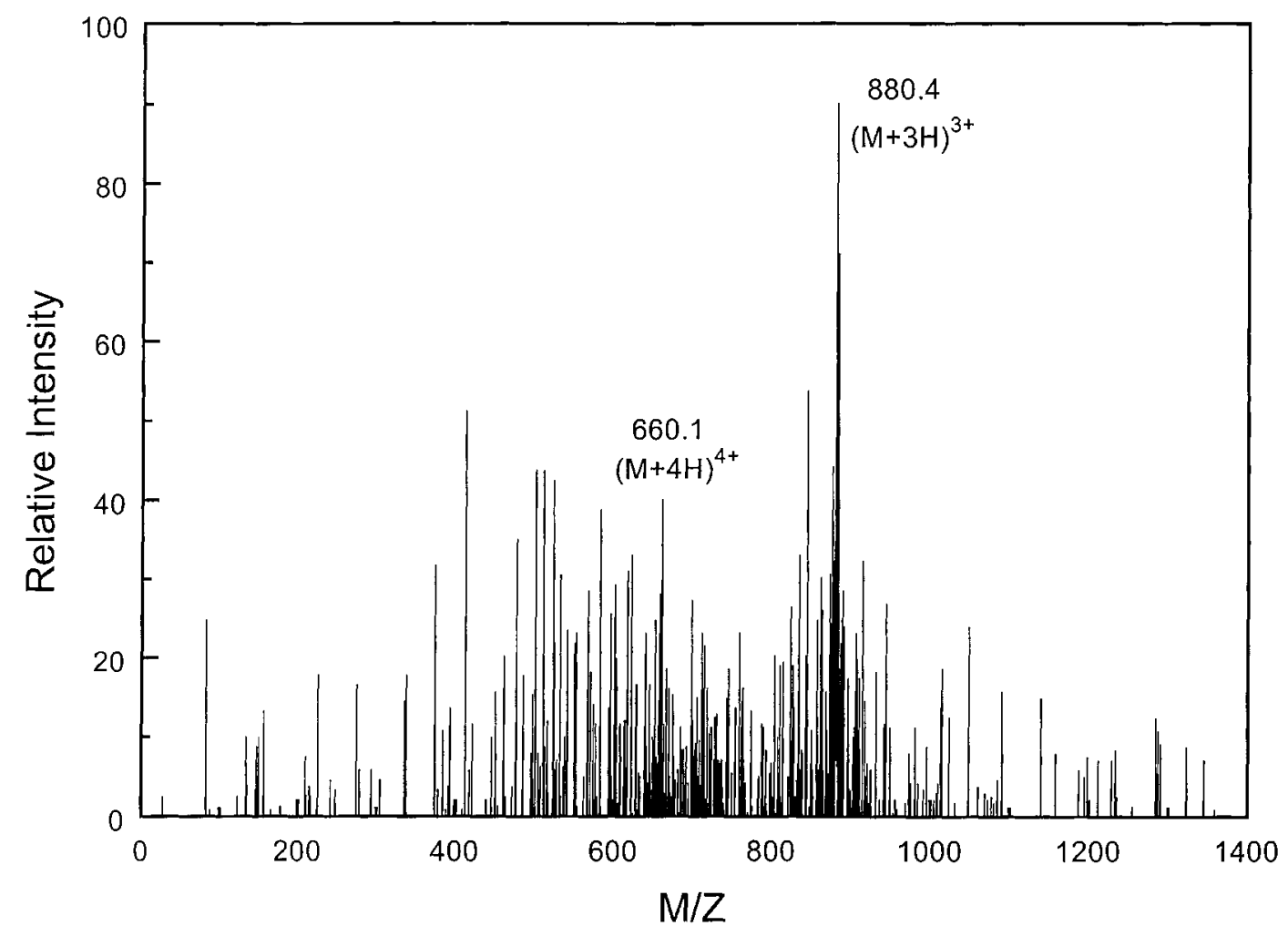

Figure 5. ESI mass spectrum of the bound analytes eluted from the immunoaffinity column, exclusively SNX-111.

plasma sample. When an aliquot $(4 \mu \mathrm{L})$ of spiked rat plasma was injected onto the immunoaffinity column, the unretained and weakly bound plasma components eluted from the $0.25 \times 150 \mathrm{~mm} \mathrm{C18}$ capillary column and were subjected directly to mass detection using ESI. By comparing the results of the plasma mixture separated only by the capillary LC/MS without the immunoaffinity column
(Fig. 3) and that with the IAC (not shown), little difference was observed, indicating that most components in the plasma were not retained on the immunoaffinity column. The pump was then switched to the capillary analytical column and a higher percentage $(30 \%)$ of acetonitrile was used to elute the immunoaffinity bound analytes. Figure 4 shows the UV and TICs of the analytes after immunoaffinity

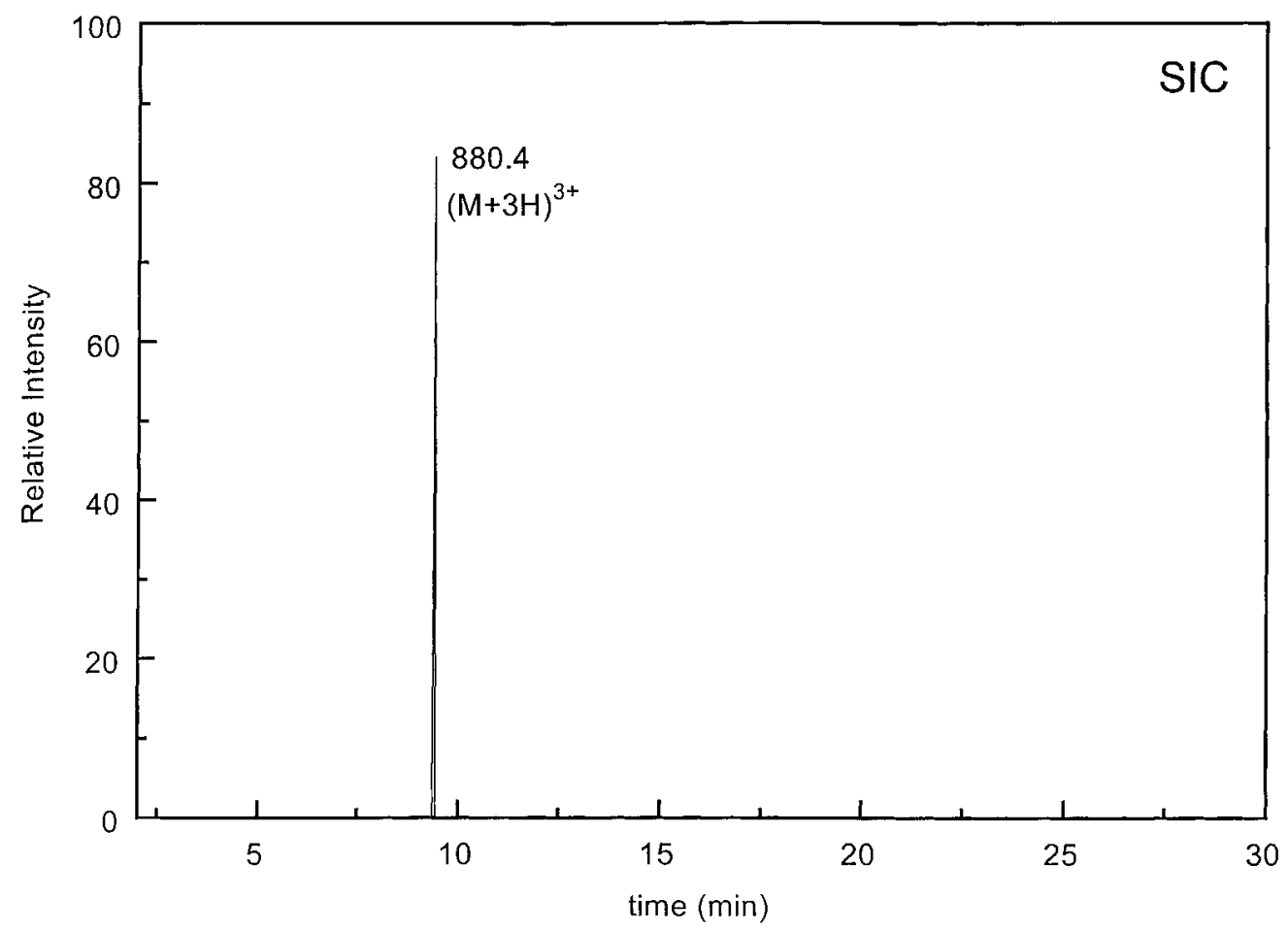

Figure 6. Reconstructed ion chromatogram of SNX-111 to go with Fig. 5. 

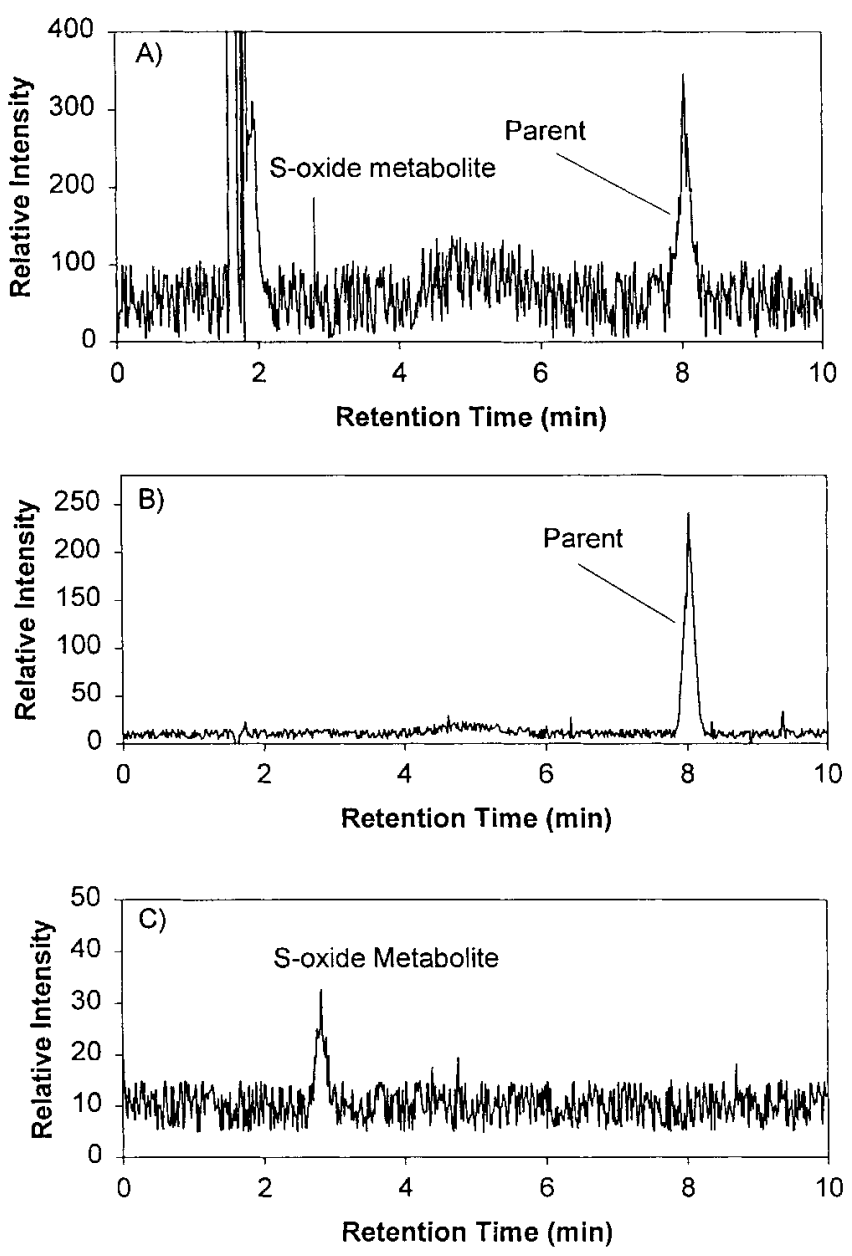

Figure 7. Ion chromatograms from immunoaffinity-reversed-phase chromatography/mass spectrometry for a rat plasma sample $1 \mathrm{~h}$ after intravenous dosing of SNX-111. (a) total ion chromatogram, (b) selected ion chromatogram $(\mathrm{m} / \mathrm{z}, 880.0)$, and (c) selected ion chromatogram $(\mathrm{m} / \mathrm{z}, 885.3)$.

extraction and reversed-phase separation, where, in each case, a peak for SNX-111 is clearly observed at $8 \mathrm{~min}$. The corresponding mass spectrum of the SNX-111 peak is shown in Fig. 5. We attribute differences between this spectrum, in which the $\mathrm{M}+3$ ion dominated, and that shown in Fig. 2, where the $M+4$ ion is dominant to solvent composition differences between the immunoaffinity/LC/ MS experiment and an LC/MS experiment where no immunoaffinity experiment was used (Figure 2). A reconstructed ion chromatogram is shown in Fig. 6.

Because of quantitation issues at this point in the study, the remainder of the mass spectrometry work was conducted using a Sciex API 365 triple quadrupole mass spectrometer. Figure 7(a) shows a TIC for a rat plasma sample from a subject animal dosed intravenously with SNX-111. The sample $(2 \mu \mathrm{L})$ was diluted with mobile-phase buffer and injected onto the $2.1 \times 100 \mathrm{~mm}$ immunoaffinity column, with subsequent separation on a $2.1 \times 250 \mathrm{~mm}$ reversedphase column. Much of the information content in this chromatogram is obscured by separation artifacts or noise. The peak at $8 \mathrm{~min}$ represents parent drug at a concentration of approximately $100 \mathrm{ng} / \mathrm{mL}(\sim 40 \mathrm{nM})$, based on a previous quantitative determination of SNX-111 in this sample. The selected ion chromatogram $(\mathrm{m} / \mathrm{z}=880.0,3+$ ion $)$ shown in Fig. 7(b) demonstrates the high selectivity for SNX-111 when a selected ion channel is monitored. Good signal-tonoise $(\mathrm{S} / \mathrm{N} \sim 25)$ was obtained for the analyte peak $(8 \mathrm{~min})$. An additional peak at $2.8 \mathrm{~min}$, not discernible in Fig. 7(a), was shown to have a mass spectrum with $\mathrm{m} / \mathrm{z}$ peaks at 885.3 and 664.3. These mass spectral features suggest the identity of this component to be the methionine $S$-oxide metabolite. Subsequent injection of a solution of the pure compound into this system confirmed this assertion. A selected ion chromatogram $(m / z$ 885.3), shown in Fig. 7(c), demonstrates a readily detectable peak with a $\mathrm{S} / \mathrm{N}$ ratio of 4 . A quantitative determination of SNX-111 in this sample suggests that the level of $S$-oxide is approximately $5 \mathrm{ng} / \mathrm{mL}$ $(2 \mathrm{nM})$. No other significant chromatographic peaks were apparent in the chromatogram, suggesting that if other metabolites were present in the sample then they were at levels below their detection limits. From the characterization of the various peptide digests shown above, it is expected that metabolites above several hundred Da would be retained and detected if present at concentration levels above the instrumental detection limits.

These results demonstrate the utility of on-line immunoaffinity liquid chromatography mass spectrometry for extracting and characterizing a parent drug and a structurally similar metabolite in a biological fluid. The on-line immunoaffinity extraction performs analyte isolation from the matrix through immunologically programmed molecular recognition. Selection between related analytes is created through a simple reversed-phase gradient separation. Analyte identification is provided by single massanalyzer mass spectrometry. In this way, it is possible to use this approach to gather metabolic information without the need for radiolabeled drug compound.

As expected, samples extracted using an IAC column indicate that greatly superior selectivity is obtained with IAC in comparison with samples directly onto a reversephase column and the SNX-111 can be readily detected in complicated matrices such as blood plasma. SNX-111 can readily be detected to a limit of $10 \mathrm{ng} / \mathrm{mL}$ or a corresponding limit of $\sim 4 \mathrm{fmol} / \mu \mathrm{L}$ using selected ion recording at 880.0 Da on the triple quadrupole mass spectrometer. We expect that results from an ion trap mass spectrometer would be similar to or better than the results obtained from these triple quadrupole experiments.

\section{CONCLUSIONS}

It appears feasible to use a combination of immobilized polyclonal antibodies (immunoaffinity chromatography) in tandem with capillary liquid chromatography and time-offlight mass spectrometry to qualitatively elucidate the metabolism of therapeutic peptides. Plasma samples can be introduced directly onto the immunoaffinity column without prior preparation. The peptide and structurally similar metabolites can be retained by the IA step while endogenous sample components are washed to waste. The analytes are then eluted from the immunoaffinity column and characterized directly by on-line liquid chromatography/mass spectrometry. One potential advantage of such a system include the possibility of performing automated sample extraction and trace enrichment with on-line mass spectral identification of peptide drugs directly from plasma or other biological fluids. A second possible advantage is the ability to elucidate peptide metabolism without the necessity for radiolabels. Although unlikely to replace this well-established approach, the immunoaffinity experiments 
could complement the use of radiolabeled compounds in situations where a radiolabeled site is lost from the peptide. We anticipate that this approach could be exploited more fully in the future.

\section{Acknowledgements}

This work received support from the National Institutes of Health under Grant R01GM49500 and from Parke-Davis Pharmaceutical Research, a division of the Warner-Lambert Company.

\section{REFERENCES}

1. Gelpi E. J. Chromatogr. 1995; 703: 59.

2. Kagel JR, Rossi DT, Nordblom GN, Dudek RC, Barksdale CM, Kuo BS, Wright DS. J. Pharm. Biomed. Anal. 1995; 13: 1205.

3. Liang X, Lubman DM, Rossi DT, Nordblom GN, Barksdale CM. Anal. Chem. 1998; 70: 498.

4. Janis LJ, Regnier FE. J. Chromatogr. 1988; 444: 1.

5. Rule GS, Henion JD. J. Chromatogr. 1992; 582: 103

6. Davoli E, Fanelli R, Bagnati R. Anal. Chem. 1993; 65: 2679.

7. Rule GS, Mordehai AV, Henion J. Anal. Chem. 1994; 64: 230.

8. Cai J, Henion J. Anal. Chem. 1996; 68: 72.
9. Lyubarskaya YV, Dunayevskiy YM, Vouros P, Karger BL. Anal. Chem. 1997; 69: 3008 .

10. Nelson RW, Krone JR, Bieber AL, Williams P. Anal. Chem. 1995; 67: 1153.

11. Papac DI, Hoyes J, Tomer KB. Anal. Chem. 1994; 66: 2609.

12. Youngquist RS, Fuentes GR, Lacey MP, Keough T. Rapid Commun. Mass Spectrom. 1994; 8: 77.

13. Barksdale CM, Nordblom GD, Miljanich GP, et al. J. Clinical Ligand Essay 1996; 19: 229.

14. Chien BM, Michael SM, Lubman DM. Int. J. Mass Spectrom. Ion Processes 1994; 131: 149.

15. Chowdhury SK, Katta V, Chait BT. J. Am. Chem. Soc. 1990; 112: 9012.

16. Edmonds CG, Loo JA, Barinaga CJ, Udseth HR, Smith RD. J. Chromatogr. 1989; 474: 21.

17. Ashton DS, Beddel CR, Cooper DJ, Green BN, Oliver RWA. Org. Mass Spectrom, 1993; 28: 579.

18. Mirza UA, Cohen SL, Chait BT. Anal. Chem. 1993; 65: 1.

19. Vorm O, Chait BT, Roepstorff P. Proc. 41st ASMS Conf. Mass Spectrometry and Allied Topics, San Francisco, CA, 1993; 621a$621 \mathrm{~b}$.

20. Smith RD, Loo JA, Ogorzalek Loo RR, Busman M. Mass Spectrom. Rev. 1991; 10: 359.

21. Proteins: Structures and Molecular Properties (2nd edn), Creighton TE (ed). W. H. Freeman and Co.: New York, 1993.

22. Katta V, Chait BT. Rapid Commun. Mass Spectrom. 1991; 5: 214. 